\title{
Comparison of chiropractic and hospital outpatient management of low back pain: a feasibility study
}

\author{
REPORT OF A WORKING GROUP
}

Membership of working group MRC Epidemiology and Medical Care Unit: Dr T W Meade (Chairman), Wendy Browne, Sandra Mellows, Joy Townsend, Janet Webb, Dr W R S North. Northwick Park Hospital: Dr A O Frank, Mr I S Fyfe, Dr K A Williams, Mr L W Lowe, (deceased 1982), Sonia Glossop, Jacqueline Hills, Dr J M Gumpel, Dr G J de Lacey. British Chiropractic Association: Mr A C Breen, Mr D L Tribe, Mr R L Cook, Mr W W Tomlin. MRC Applied Psychology Unit: Dr A D Baddeley.

SUMMARY This is the report of a feasibility study of a randomised controlled trial of chiropractic and hospital outpatient management for low back pain of mechanical origin. Preparations for the study included an approach to the General Medical Council for guidance about the intended collaboration between medically qualified and heterodox practitioners, detailed communication with local general practitioners, and the provision of a Medical Research Council (MRC) grant to cover payments to the chiropractors for work carried out in the course of the study. A total of 238 patients were considered, 197 of whom had initially presented to Northwick Park Hospital and the remaining 41 to the chiropractic clinic in Harrow. Only $6 \%$ of the patients presenting to the hospital refused to enter. The single most frequent reason for ineligibility in the hospital patients was freedom from pain at the time of the first hospital visit (23\%). A variety of medical contraindications accounted for the exclusion of a further $24 \%$ of hospital patients. Patients presenting to the chiropractic group tended to have had shorter current episodes of back pain but to have had more NHS treatment in the past than those presenting to hospital. The commonest reason for exclusion among those presenting to the chiropractic clinic was refusal to enter (34\%). Only $5 \%$ of the chiropractic patients were ineligible for medical reasons. Overall, $16 \%$ of those presenting to hospital and $44 \%$ of those presenting to the chiropractors were eligible and willing to enter the randomised treatment phase of the study. Of the 50 patients who entered the treatment phase, all but seven completed treatment and the six weekly self-completed assessments of progress. Patients whose current episodes had lasted less than a month progressed significantly more rapidly than those with longer current episodes. It is likely that sufficient numbers of patients with low back pain are prepared to take part in a formal randomised controlled trial. The organisation and working methods for such a trial appear to be feasible. A full scale multicentre trial should aim to include about 2000 patients.

Back pain is a leading cause of morbidity and of absence from work. ${ }^{1}$ Randomised controlled trials have not clearly established the superiority of any particular treatment ${ }^{2-4}$ although at least one ${ }^{4}$ has suggested that manipulation may be marginally more effective than some other methods. Patients often refer themselves to practitioners of alternative medicine, and striking accounts of apparently rapid symptomatic improvement after treatment by chiropractors or osteopaths are frequent.
In 1981, the MRC Epidemiology and Medical Care Unit was consulted by the British Chiropractic Association about the evaluation of chiropractic in the treatment of low back pain of mechanical origin. It was agreed that this could only satisfactorily be approached through a randomised controlled trial and that a feasibility study would be necessary to answer a number of questions on which the viability of a definitive trial would depend. This paper describes the planning, conduct, and conclusions of 
such a feasibility study. The main objectives were:

i To see if patients were prepared to take part in a trial in which their assignment to either orthodox or heterodox treatment would be made at random.

ii To establish and test the working methods for a trial.

iii To estimate the number of patients required for a full-scale trial.

Through the British Chiropractic Association, contact was made with the chiropractic group in Harrow, a branch of the main practice in Berkhamsted, and the three partners agreed to take part. The study began in February 1983, the aim being to recruit 50 patients, an arbitrary number but likely to be large enough to test feasibility. Patients came from a special back clinic and an orthopaedic clinic at Northwick Park Hospital and from the Harrow chiropractic clinic. It was agreed that the study would be one of different policies, ie, of chiropractic and hospital management, rather than of specific treatments. Each clinic, chiropractic or hospital, was thus free to treat individual patients according to their usual practices.

It is widely believed that doctors in the UK are prohibited from collaborating with heterodox practitioners. This is not in fact so, provided certain conditions are met. In order to ensure that these conditions were fulfilled in this particular case, a formal approach to the General Medical Council was made by Medical Research Council Headquarters Office for guidance. In summary, there were two aspects which required particularly careful attention. The first was that the doctors who would be taking part should satisfy themselves about the adequacy of the clinical and therapeutic facilities provided by the chiropractors. This was approached by a series of exchange visits between the chiropractors and staff at Northwick Park Hospital, during which the selection of suitable patients, their radiological and laboratory investigation, and their treatment were discussed and demonstrated. The second concerned communication between the hospital specialists and general practitioners. Since many patients refer themselves to chiropractors without consulting a doctor, arrangements had to be made to ensure that their inclusion in the study would nevertheless meet with the approval of their general practitioners. Accordingly, the study was first discussed with representatives of the local general practitioners. A letter was then sent to each of the 100 or so general practitioners in Harrow, describing the study and giving the doctor an opportunity to state at the outset that none of his or her patients should be entered. No doctor took up this option. Several wrote back to say that a study of the kind being proposed was overdue and offered their full cooperation. Besides having this general opportunity to opt out, general practitioners were then approached over each eligible patient, and approval to enter that particular patient was sought. (This was, of course, the only opportunity to seek approval from general practitioners outside the Harrow area.) Consent to entry was withheld on only one occasion, for an entirely valid reason. The Harrow District Ethical Committee deferred a decision about the study when it first considered the proposal because of concern about possibly inappropriate media coverage of the results. After full discussion about this aspect at a second meeting, the study was approved.

It was agreed that all patients, whether presenting initially to the chiropractic slinic or to Northwick Park Hospital, should be $x$-rayed at Northwick Park. Accordingly, arrangements were made in the Radiology Department of Northwick Park to ensure that all trial participants were seen quickly, since delays would obviously deter the participation of patients presenting initially to the chiropractic clinic.

An MRC grant covered the payments to the chiropractors for the patients they treated in the course of the study.

\section{Methods}

Details of new patients with back pain were recorded by the chiropractors and by the participating doctors at Northwick Park. Since the Harrow chiropractic clinic is a branch practice dealing with limited numbers, it was considered that it would also be valuable to record patients with low back pain at a main chiropractic clinic. Accordingly, details of patients presenting to the chiropractic clinic in Salisbury, Wilts, were recorded for a month, and these patients were also asked whether they would have been willing to take part in a trial. (This is the clinic of the British Chiropractic Association member of the Working Group not working in Harrow.)

Patients who appeared eligible were interviewed by the nurse coordinator who explained the purpose of the study and pointed out that agreement to take part involved an equal chance of being treated by chiropractic or by conventional hospital methods, the decision being made at random. Patients were told that if they were allocated for treatment to the clinic they had not originally attended, they would be free at any stage to return to the original clinic. Those who agreed to take part were then $x$-rayed at Northwick Park. Films were reported by the consultant radiologist participating in the study and were reviewed by medical staff in the Northwick Park back clinic to determine final eligibility. Permission was sought from the patient's general practitioner. The 
patient was then allocated at random for treatment either at the chiropractic clinic or at Northwick Park Hospital. The method of minimisation ${ }^{5}$ was used to ensure balance between the two treatment groups in terms of referral clinic, length of the current episode (more or less than a month), any past history of back pain, and an Oswestry score (see below) of more or less than $40 \%$. Patients then attended for treatment. As already indicated, the nature and duration of treatment were at the discretion of those concerned, full details being recorded in each case. Chiropractic treatment almost always involves graded manipulation. Treatment at Northwick Park (as elsewhere) involves a wide range of procedures, including exercises, traction, manipulation, hydrotherapy, and back education classes, and may include immobilisation.

The main measure of progress was the Oswestry back pain questionnaire. ${ }^{6}$ This uses a scoring system for each of 10 sections (eg, pain intensity, difficulty with lifting, walking or travelling). The result is expressed on a scale ranging from $0 \%$ (no pain or difficulties) to $100 \%$ (highest score for pain or difficulty on all items). Each patient completed this questionnaire at entry. Further questionnaires were then sent by post, with prepaid reply envelopes, at weekly intervals for six weeks and, finally, at six months. The purpose of sending weekly questionnaires was to estimate speed of recovery, as well as the proportion of patients who had improved at six weeks, which was initially considered to be the time of termination in the study (though this decision may be revised in a main trial). During the course of the study, a second questionnaire was introduced. This was a modification of the St Thomas' questionnaire $^{7}$ based on Yes/No answers to a range of questions similar in some respects to those in the Oswestry questionnaire but also including other items. A considered decision was taken not to include clinical measures such as the straight leg raise as outcome measures.

\section{Results}

Figure 1 shows the numbers and other details of patients with low back pain presenting to the two clinics during the period (February-November 1983) required for the recruitment of 50 patients into the randomised treatment stage. The relatively small number considered by the chiropractic clinic reflects its status as a branch practice. Of the 197 Northwick Park patients considered, $150(76 \%)$ were ineligible. Although eligible, $12(6 \%)$ declined to enter the randomised phase. In three cases, the study was "closed", ie, recruitment had been temporarily suspended because of inability to deal with further patients from time to time. The pattern was quite different in the 41 chiropractic clinic patients. Here, only nine $(22 \%)$ were ineligible but $14(34 \%)$ declined to enter. Results from the Salisburyd chiropractic clinic were similar. Of 44 patients, 13त्षे $(29 \%)$ were ineligible and $17(39 \%)$ would have refused to enter a randomised treatment comparison. Thus, 32 Northwick Park patients $(16 \%)$ wereo eligible and willing to enter the randomiseds treatment phase compared with $18(44 \%)$ from theo Harrow chiropractic clinic. Figure 1 also shows the numbers from each clinic according to eventual place of treatment.

Table 1 compares some of the characteristics of the two groups of patients considered for the randomised treatment phase. The mean ages and age

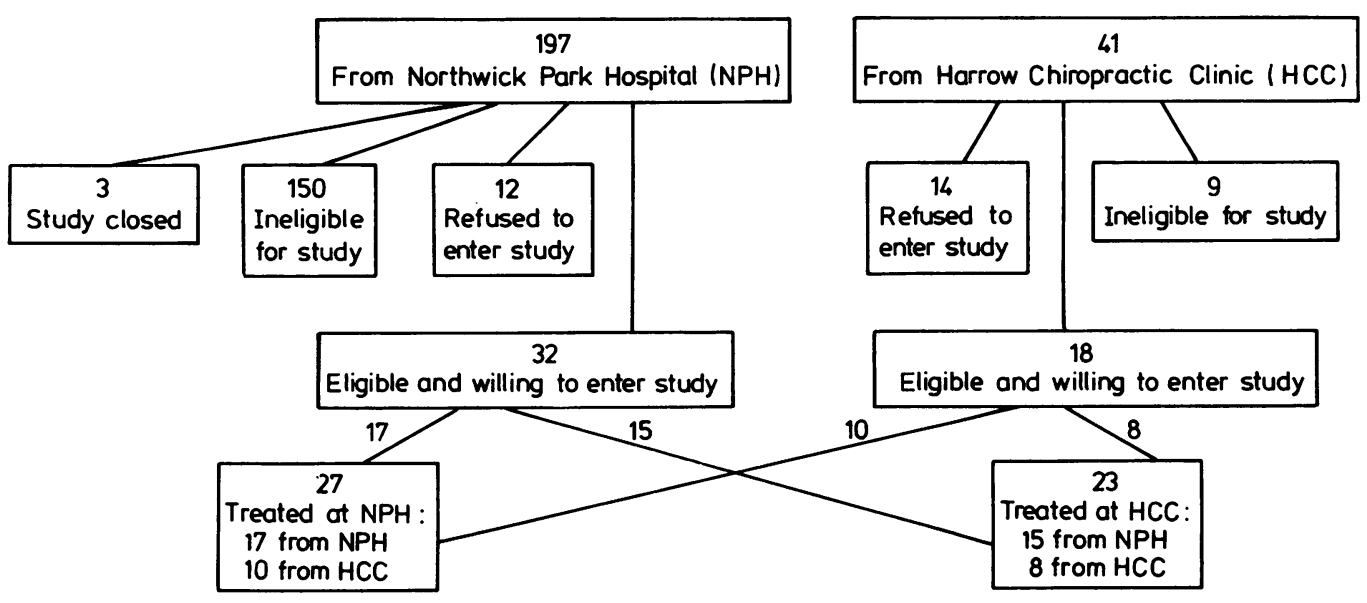

Fig 1 Patients considered for the study. 
Table 1 Patients considered

\begin{tabular}{lll}
\hline & \multicolumn{2}{l}{ Referral centre } \\
\cline { 2 - 3 } & $\begin{array}{l}\text { Northwick Park } \\
(N=197)\end{array}$ & $\begin{array}{l}\text { Harrow Chiropractic } \\
\text { Clinic } \\
(N=41)\end{array}$ \\
\hline $\begin{array}{l}\text { Mean age (years) } \\
\text { Mean age of onset of } \\
\text { back pain (years) }\end{array}$ & 46.3 & 46.9 \\
$\begin{array}{c}\text { Median duration of current } \\
\text { episode (weeks) }\end{array}$ & 37.3 & $38 \cdot 7$ \\
$\begin{array}{c}\text { Median duration of history } \\
\text { (months) }\end{array}$ & $16 \cdot 7$ & $5 \cdot 5$ \\
$\begin{array}{c}\text { Previous history of back pain } \\
\text { Treated for current or } \\
\text { previous episodes* }\end{array}$ & $75 \%$ & 72.0 \\
$\begin{array}{c}\text { Patients treated who had } \\
\text { previous NHS treatment }\end{array}$ & $79 \%$ & $83 \%$ \\
$\begin{array}{c}\text { Patients treated who had } \\
\text { previous chiropracticl } \\
\text { osteopathic treatment }\end{array}$ & $27 \%$ & $85 \%$ \\
\hline
\end{tabular}

$* p=0.0005$

distributions of the two groups were very similar, as were the ages of onset of back pain. The distributions of the length of back pain history and length of current attack were skewed for both groups of patients and so the medians, rather than the means, are presented. The median length of back pain history was 60 months for those presenting to Northwick Park, compared with 72 months in those presenting to the chiropractic clinic, but the difference was not significant. However, the difference between the median duration of the current episode in the two groups was highly significant (Mann-Whitney test). Expressed another way, the current episode had lasted no longer than five weeks for $50 \%$ of chiropractic patients, compared with only $13 \%$ for the hospital patients.

Among all 238 patients (120 men and 118 women), current episodes tended to be longer for women than for men. The median length of current episodes was 13 weeks for men and 20.5 weeks for women (Mann-Whitney test: $p=0 \cdot 01$ ). The current episode had lasted longer than 20 weeks in $50 \%$ of the women compared with $30 \%$ of the men.

The relative prevalence of a previous history of back pain for the two sexes was significantly different in the two clinics; the prevalence for men was higher than for women $(83 \%$ compared with $68 \%)$ in those presenting to Northwick Park, whereas the prevalence for men was lower than for women $(77 \%$ compared with 93\%) in those presenting to the chiropractic clinic (logistic regression test for the interaction: $p<0.05$ ).

Table 2 summarises information about the patients who entered the randomised treatment phase. The findings are similar to those in table 1, though they are, of course, based on much smaller numbers. Mean Oswestry score at entry was higher in the
Table 2 Patients entered

\begin{tabular}{|c|c|c|}
\hline & \multicolumn{2}{|l|}{ Referral centre } \\
\hline & $\begin{array}{l}\text { Northwick Park } \\
(N=32)\end{array}$ & $\begin{array}{l}\text { Harrow Chiropractic } \\
\text { Clinic } \\
(N=18)\end{array}$ \\
\hline Mean age (years) & 42.5 & $49 \cdot 1$ \\
\hline $\begin{array}{l}\text { Mean age of onset of } \\
\text { back pain (years) }\end{array}$ & $34 \cdot 0$ & $40 \cdot 5$ \\
\hline $\begin{array}{l}\text { Median duration of current } \\
\text { episode (weeks) }\end{array}$ & $28 \cdot 2$ & $6 \cdot 0$ \\
\hline $\begin{array}{l}\text { Mean Oswestry Score at entry } \\
\text { Median duration of history }\end{array}$ & $22 \cdot 1$ & $27 \cdot 4$ \\
\hline (months) & $60 \cdot 0$ & $96 \cdot 0$ \\
\hline $\begin{array}{l}\text { Previous history of back pain } \\
\text { Treated for current or }\end{array}$ & $66 \%$ & $72 \%$ \\
\hline $\begin{array}{l}\text { previous episodes* } \\
\text { Patients treated who had }\end{array}$ & $53 \%$ & $72 \%$ \\
\hline $\begin{array}{l}\text { previous NHS treatment } \\
\text { Patients treated who had } \\
\text { previous chiropracticl }\end{array}$ & $71 \%$ & $85 \%$ \\
\hline $\begin{array}{l}\text { osteopathic treatment } \\
\text { Mean improvement in }\end{array}$ & $41 \%$ & $39 \%$ \\
\hline $\begin{array}{l}\text { Oswestry Score between } \\
0 \text { and } 6 \text { weeks }\end{array}$ & $3 \cdot 0$ & $10 \cdot 7$ \\
\hline
\end{tabular}

chiropractic referrals, and their mean improvement over six weeks was greater. Details are not shown, but in terms of treatment allocation (as distinct from comparison by referral clinic) there were no major imbalances between those managed by the chiropractors or at Northwick Park.

Table 3 summarises reasons for refusal to enter in patients who were otherwise eligible. Unwillingness to participate was commoner in the patients presenting to the chiropractic clinic and was due mainly to a wish to avoid further delay, even of a day or so, in starting treatment. Table 4 summarises the reasons for ineligibility. This is dominated by the patients referred to Northwick Park (see also fig 1). The single main reason was freedom from pain at the time of initial interview in $23 \%$ of the hospital patients. Neurological deficit (such as impaired reflexes) or sciatica with a straight leg raise of less than 60 degrees accounted for a further $17 \%$ of the hospital patients. There was a wide range of other reasons for small numbers of further exclusions.

Table 3 Reasons for refusal to enter

\begin{tabular}{|c|c|c|c|c|c|c|}
\hline & \multicolumn{6}{|c|}{ Number of patients } \\
\hline & \multicolumn{2}{|c|}{ Hospital } & \multicolumn{2}{|c|}{$\begin{array}{l}\text { Chiropractic } \\
\text { Clinic }\end{array}$} & \multicolumn{2}{|c|}{ Total } \\
\hline & $N$ & \% & $N$ & $\%$ & $N$ & \% \\
\hline $\begin{array}{l}\text { Patient unwilling to participate } \\
\text { Previous unsuccessful } \\
\text { chiropractic/osteopathic } \\
\text { treatment }\end{array}$ & 7 & 3.6 & 8 & $19 \cdot 5$ & 15 & $6 \cdot 3$ \\
\hline Previous unsuccessful & 3 & 1.5 & 0 & 0 & 3 & $1 \cdot 3$ \\
\hline NHS treatment & 0 & 0 & 3 & $7 \cdot 3$ & 3 & $1 \cdot 3$ \\
\hline Other reasons & 2 & $1 \cdot 0$ & 3 & $7 \cdot 3$ & 5 & $2 \cdot 1$ \\
\hline Totals & 12 & $6 \cdot 1$ & 14 & $34 \cdot 1$ & 26 & $10 \cdot 9$ \\
\hline
\end{tabular}

Percentages are of all 197 patients in hospital and 41 in chiropractic clinic. 
Table 4 Reasons for ineligibility

\begin{tabular}{|c|c|c|c|c|c|c|}
\hline & \multicolumn{6}{|c|}{ Number of patients } \\
\hline & \multicolumn{2}{|c|}{ Hospital } & \multicolumn{2}{|c|}{$\begin{array}{l}\text { Chiropractic } \\
\text { Clinic }\end{array}$} & \multicolumn{2}{|c|}{ Total } \\
\hline & $N$ & $\%$ & $N$ & $\%$ & $N$ & $\%$ \\
\hline Pain free & 45 & $22 \cdot 8$ & 2 & $4 \cdot 9$ & 47 & $19 \cdot 7$ \\
\hline Neurological deficit & 17 & $8 \cdot 6$ & 0 & 0 & 17 & $7 \cdot 1$ \\
\hline Sciatica with SLR $<60^{\circ}$ & 16 & $8 \cdot 1$ & 0 & 0 & 16 & 6.7 \\
\hline Spondylolisthesis/spondylolysis & 7 & $3 \cdot 6$ & 2 & 4.9 & 9 & $3 \cdot 8$ \\
\hline Spondylo-arthropathy & 3 & $1 \cdot 5$ & 0 & 0 & 3 & $1 \cdot 3$ \\
\hline Osteopenia & 4 & $2 \cdot 0$ & 0 & 0 & 4 & $1 \cdot 7$ \\
\hline $\begin{array}{l}\text { Treated by chiropractor/ } \\
\text { osteopath in previous month }\end{array}$ & 5 & $2 \cdot 5$ & 0 & 0 & 5 & $2 \cdot 1$ \\
\hline Psychosocial problems & $\begin{array}{l}5 \\
6\end{array}$ & $\begin{array}{l}2 \cdot 5 \\
3 \cdot 0\end{array}$ & $\begin{array}{l}0 \\
0\end{array}$ & $\begin{array}{l}0 \\
0\end{array}$ & $\begin{array}{l}5 \\
6\end{array}$ & $2 \cdot 5$ \\
\hline Other reasons* & 47 & 23.9 & 5 & $12 \cdot 2$ & 52 & $21 \cdot 8$ \\
\hline Totals & 150 & $76 \cdot 0$ & 9 & $22 \cdot 0$ & 159 & 66.8 \\
\hline
\end{tabular}

*Other reasons include cancer, infirmity, complicated medical history, not a back problem.

Percentages are of all 197 patients in hospital and 41 in chiropractic clinic.

Seven patients failed to complete the main six-week study. Of these, four had been referred to and were being treated at Northwick Park. The other three had initially presented at the chiropractic clinic, one being treated there and the other two at Northwick Park. Twelve of the 50 patients did not return a completed questionnaire at six months (though no reminders were sent at this stage).

Progress for all the patients in the randomised treatment phase (ie, regardless of place of treatment) is summarised in figs 2 and 3 in terms of the Oswestry Questionnaire. Figure 2 shows that for both those with and without a previous history of back pain, there was a slow but fairly steady decline from an initial mean score for all patients of $24 \%$ at entry to about $18 \%$ at six weeks, with a further decline to about $15 \%$ between six weeks and six months. Figure 3 shows progress according to the duration of current episode at the time of entry to the study. Scores at entry were similar for those whose current episode had lasted more or less than a month but progress was clearly much more rapid and complete for those with short episodes. The extent of improvement for patients initially referred to the chiropractic clinic was also much more rapid than for hospital referrals (see table $2 ; p=0 \cdot 06$ ). However, within each of these two groups those with a shorter current episode showed more rapid improvement. It appears that the type of patient, ie, hospital or chiropractic referral, as well as duration of current episode both contribute to the rate of improvement.

\section{Discussion}

In the patients presenting to Northwick Park, much the commonest reason for not entering the randomised treatment phase was ineligibility. A substantial number of the hospital patients $(23 \%)$

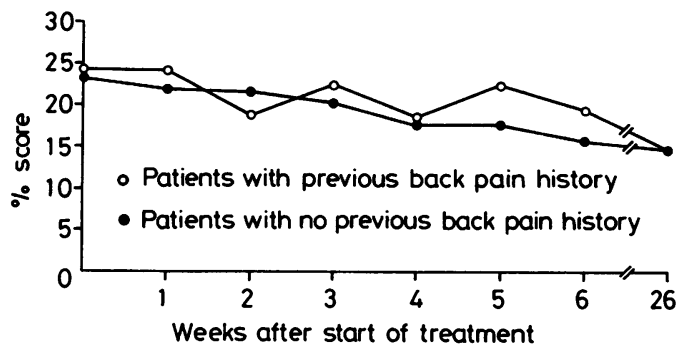

Fig 2 Progress according to past history of back pain.

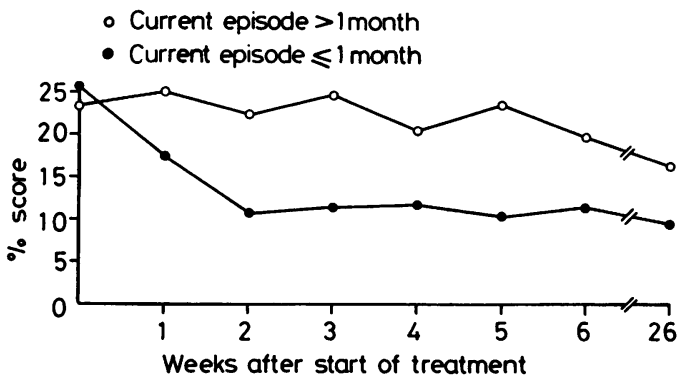

Fig 3 Progress according to duration of current episode.

were in fact free of pain by the time they were seen ir the clinic. The second main reason was related to the severity of the condition in terms of the originat criteria for eligibility. However, as the study progressed it was increasingly felt that some of these criteria could be relaxed, and towards the end of the recruitment phase patients with sciatica and a straight leg raise of less than 60 degrees were considered eligible (provided there were no signs of neurological deficit). It is not surprising that ineligibility for medical reasons should predominate in patients referred to hospital. Equally, it is not surprising that unwillingness to enter the study predominated in patients initially attending the chiropractic clinic since many of these patients refer themselves in order to secure immediate attention. (Although the median duration of the current episode was shorter in those presenting to the chiropractic group than to the hospital, a substantial proportion of back pain patients seen by chiropractors have chronic ${ }^{8}$ rather than short-term histories.)

The very different progress of patients according to the duration of the present episode (fig 3 ) is clear but its interpretation is uncertain. Oswestry scores at entry were similar. If the only difference between the two groups was in terms of the duration of the episode, the entry score for those with a short duration would presumably have been higher, given the natural tendency for the condition to remit spontaneously. It is therefore possible that the two 
groups represent two fairly distinct types of back pain.

In a multicentre trial, the numbers of patients available in any individual centre (ie, hospital and chiropractic clinics in the same town) will depend on the numbers initially seen at either the hospital or the chiropractic clinic and the proportions eligible in each case. In the feasibility study, the absolute number of referrals to the chiropractic clinic was small in relation to the number of referrals to Northwick Park, but the proportion of patients entered into the trial was larger. The results from the Salisbury chiropractic clinic were similar to those from the chiropractic clinic in Harrow in terms of the proportions of patients ineligible, refusing or entering the feasibility study. Our experience suggests that about $25 \%$ of patients with back pain would be eligible and willing to enter a trial, though this figure would probably be larger in a centre where relatively more patients presenting to a chiropractic group were available. It is often considered that trials are only justifiable if a very high proportion of those with the condition in question can be recruited. However, treatment may be very effective in a minority of patients to whom it can be applied. ${ }^{9}$ It has so far been the exception rather than the rule for trials to provide information on the proportion of all the patients with the condition in question who are actually recruited. Where these details are recorded, it is common experience that only a minority can be entered. ${ }^{10} \mathrm{~A}$ multicentre trial does appear to be justified in terms of the three main objectives for study at this feasibility stage. Thus, patients are willing to enter a randomised treatment comparison among both those presenting to a district general hospital and to a chiropractic clinic. The practical conduct of the feasibility study presented no insoluble difficulties. Any main trial would probably need about 2000 patients in all. Such a trial would, of course, only establish the relative merits of the two different approaches.

One of the questions raised by the feasibility study is the apparently low level of pain/disability indicated by the Oswestry questionnaire. It may be that pain equivalent to an Oswestry score of about $25 \%$ that is experienced over a long period of time is of sufficient concern to the patient to justify seeking treatment. However, attention would be given in any main trial to the possible recruitment of a higher proportion of patients with more acute, short term episodes.

In order to avoid the possibility that preliminary indications might bias the conduct of any main trial, results by randomised treatment group during the feasibility study will not be disclosed.

\section{References}

${ }^{1}$ Working Group on Back Pain. Report to Secretary of State for Social Services. Department of Health and Social Security. HMSO, 1979.

${ }^{2}$ Doran DML, Newell DJ. Manipulation in treatment of low back pain: a multicentre study. $B r$ Med J 1975; 2: 161-4.

${ }^{3}$ Sims-Williams $\mathbf{H}$, Jayson MIV, Young SMS, Baddeley $\mathrm{H}$, Collins E. Controlled trial of mobilisation and manipulation for low back pain: hospital patients. $\mathrm{Br}$ Med J 1979; 2: 1318-20.

${ }^{4}$ Coxhead CE, Inskip H, Meade TW, North WRS, Troup JDG. Multicentre trial of physiotherapy in the management of sciatic symptoms. Lancet 1981; 1: 1065-8.

${ }^{5}$ Pocock SJ, Simon R. Sequential treatment assignment with balancing for prognostic factors in the controlled clinical trial. Biometrics 1975; 31: 103-15.

${ }^{6}$ Fairbank J, Davies J, Coupar J, O'Brien J. The Oswestry low back pain disability questionnaire. Physiotherapy 1980; 66: 271-3.

${ }^{7}$ Roland M, Morris R. A study of the natural history of low back pain-part 1: development of a reliable and sensitive measure of disability in low back pain. Spine 1983; 8: 141-50.

${ }^{8}$ Breen AC. Chiropractors and the treatment of back pain. Rheumatol Rehabil 1977; 16: 46-53.

${ }^{9}$ Smith DS, Goldenberg E, Ashburn A, Kinsella G, Sheikh K, Brennan PJ, Meade TW, et al. Remedial therapy after stroke: a randomised controlled trial. $\mathrm{Br} \mathrm{Med} J \mathrm{~J}$ 1981; 282: 517-20.

${ }^{10}$ Charlson ME, Horwitz RI. Applying results of randomised trials to clinical practice: impact of losses before randomisation. $\mathrm{Br} \mathrm{Med} J$ 1984; 289: 1281-4. 